INTERNATIONAL JOURNAL OF SCIENTIFIC RESEARCH

\title{
A RARE CASE OF RECURRENT NASAL SCHWANOMA
}

\section{Otolaryngology}

Shubhangi Gupta* Sawai Man Singh Medical College And Attached Hospitals, Jaipur*Corresponding

Gaurav Singhal $\quad$ Sawai Man Singh Medical College And Attached Hospitals, Jaipur

\section{Vijay Kumar}

Sharma
Sawai Man Singh Medical College And Attached Hospitals , Jaipur

\section{ABSTRACT}

Schwanoma are neurogenic tumors which are rarely found in nose and paranasal sinus . A 65 year old male presented with chronic rhinosinusitis affecting his right nose. He has transnasal surgery for the same complaint. Histopathological report suggestive of schwanoma which was positive for SOX-10 and S-100 on immunohistochemistry. The lesion was removed by endoscopic sinus surgery with debridment. The patient made good post- operative recovery and remained diseased free at six months follow- up

\section{KEYWORDS}

Recurrent nasal schwanoma, S-100, SOX-10, benign tumor

\section{Introduction}

Schwanoma are benign tumours originating from peripheral nerve sheaths. Previous reports indicate that $25-50 \%$ of schwanomas occur in the head and neck region, but tumours originating from the nasal cavity or paranasal sinuses are rare, with a reported rate of approximately $4 \%[1,2]$.

We present a case of recurrent nasal schwanoma in a 65 year old male which was excised endoscopically.

\section{Case Report}

A 62 year old male was referred to V.S Hospital, Ahmedabad in June 2015 complaining of recurrent swelling near right eye, nasal bridge widening causing deviation of nose to left side, nasal blockade, nasal discharge, watering from right eye with anosmia. He had the prior surgical history for the same complaint in 2002 at different setup. The histopathological specimen of the excised specimen revealed the spindle cell neoplasm with moderate to marked nuclear atypia with SOX -10 and $\mathrm{S}-100$ (Schwanoma marker) positive on immunohistochemistry.

External examination showed $3 * 3 \mathrm{~cm} 2$ non-tender firm swelling on medial canthus of right eye extending to nasal dorsum. [FIG.1]

Anterior rhinoscopy showed painless, pale, firm lobulated mass in the right nasal cavity with deviation of nasal septum towards left side.

On Ophathamic evaluation, finger counting was more than three feet for both the eyes .

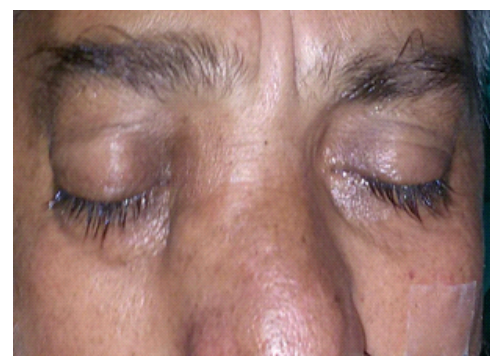

[FIG.1]

The computed tomography with contrast of nose and paranasal sinus showed $76^{*} 28 \mathrm{~mm}$ well- defined lobulated mass with heterogenous post - contrast enhancement in the right nasal cavity . Superiorly, the lesion was extending into right and left anterior ethmoidal and bilateral frontal sinus . Laterally it was extending into right maxillary sinus along with lateral bowing of right lamina paperycea. Posteriorly , it was reaching upto right posterior ethmoidal and bilateral sphenoidal sinus . Right cribriform plate and anterior skull base appeared destroyed. [FIG. 2]

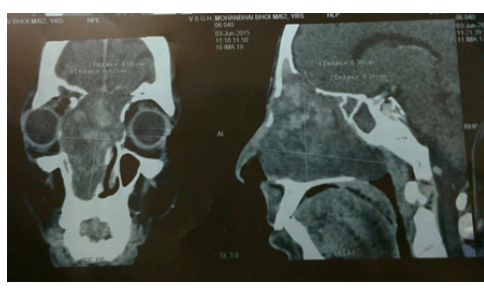

[FIG.2]

The Magnetic resonance imaging brain showed $63 * 38 * 65$ heterogenous expansile mass on T1W and $\mathrm{T} 2 \mathrm{~W}$ sequence. The lesion had the mass effect in the form of lateral bowing of medial wall of the right orbit. There was compression on the right medial rectus and eyeball. The nasal septum was displaced to left side by the lesion. Superiorly, the mass was abutting the floor of anterior cranial fossa Inferiorly, it was extending upto right hard palate . Bilateral optic nerve was normal with no intracranial extension. [FIG. 3]
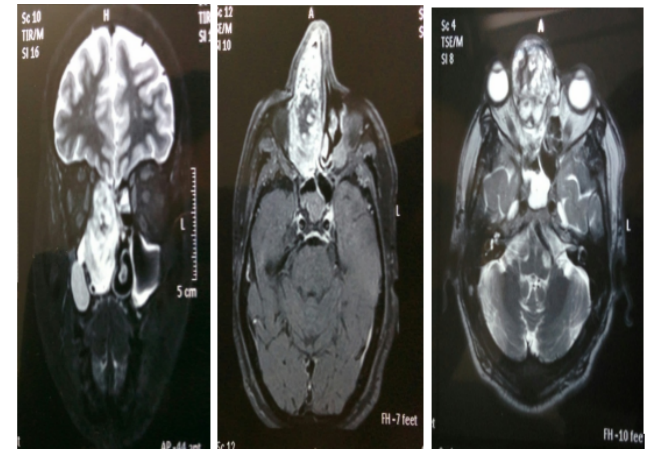

[FIG.3]

Surgical excision of the mass was planned under general anaesthesia . Informed consent was taken from the patient. Complete debridment of the lesion was done through trans nasal endoscopic approach. Exposed dura was covered by surgicel followed by abgel. Nasal packing was done with merocele

Post-operatively the patient condition was uneventful.

The excised specimen was sent for microscopic examination which confirmed the diagnosis of schwanoma [same as previous report].

There was no CSF leak and recurrence at six months follow up.

\section{Discussion}

Unilateral tumours in the nasal cavity causing nasal obstruction, pain, fullness, and epistaxis are usually caused by benign disease processes such as polyps, cysts, and mucoceles. A unilateral tumour originating from the nasal cavity should also stimulate the consideration of the rare 
esthesioneuroblastoma, a neoplasm originating from the olfactory neuroepithelium that has significant heterogeneity in management and variation in prognosis [3].

Schwanoma of nose and paranasal sinuses present with similar findings but are very rare.

A schwanoma is a benign tumor is only seen arising from the nerve sheath; thus, it is only seen in myelinated nerves. In the head and neck region, the most common site is the eighth cranial nerve (vestibulocochlear); other sites include the scalp, face, parotid gland, oral cavity, pharynx, larynx, and trachea [4]. The optic and olfactory cranial nerves are not potential sites of the origin, since they lack sheaths that contain schwann cells and since nasal schwanomas are sometimes removed without loss of original nerve functions, it is usually difficult to determine the neural origin. Nasal schwanomas are presumed to be arising from the sheath of the ophthalmic and maxillary branches of the trigeminal nerve and autonomic ganglia [5] .

The literature mentions approximately only 70 cases of nose and paranasal sinus schwanomas that are mostly seen in adults aged 40-60 years and without gender or racial predilection [6]. The most commonly involved sinus is the ethmoid sinus, followed by the maxillary sinus, nasal cavity, and sphenoid [7].

Patient may complain of nasal obstruction, epistaxis, rhinorrhoea, anosmia, facial swelling or pain [8].

Computerized tomography(CT) delineates an image of the soft tissue tumor and simultaneously outlines the skeletal margins well enough to rule out invasion and demonstrated central lucency and peripheral enhancement after contrast administration in case of schwanomas because peripheral neovascular areas of the tumor are enhanced in contrast with nonenhancing necrotic or cystic regions[9]. Although magnetic resonance imaging (MRI) is superior in defining soft tissue tumors, CT offers better resolution of bony invasion. However, as benign schwannoma can erode bone by pressure, bony erosion is not a criterion for malignancy [10]. With either approach, final diagnosis rests solely on the histologic examination.

Macroscopically schwanomas appear as gelatinous or cystic well encapsulated masses. Microscopically schwanomas are classified into three major histological types [11]. Hypercellular or Antony A areas comprised of spindle shaped cells arranged in interlacing fascicles and hypocellular or Antony B areas where the cells are present in a loose myxoid stroma. Parallel rows of palisading nuclei (verocay body) can be seen in highly differentiated tissue [FIG. 5(a)]. The differential diagnosis includes inflammatory polyps, angiofibroma, inverted papilloma, meningiomas, neurofibroma, melanoma and neuroblastoma $[11,12]$. Histopathology remains gold standard for the diagnosis. Schwannomas usually show intense immunostaining for S100 which helps to distinguish peripheral nerve sheath tumour from others [FIG.5(b) ]. The treatment is complete surgical excision which is determined according to the location and extent of lesion. Though recurrence is rare after removal, there are reports of malignant changes in long standing benign schwannoma [13]. Hence, long term and intimate follow up is required. There was recurrence after thirteen years of surgical debridment in our case which was re-explored and again the surgical clearance was done. Till date, no recurrence is there.

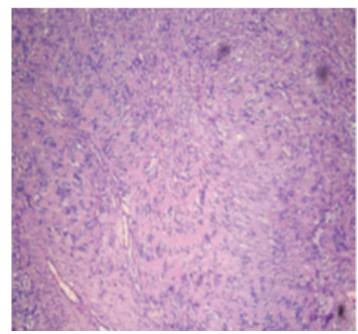

(a)

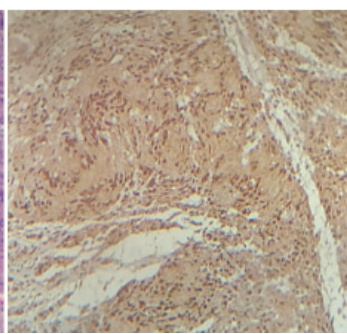

(b)
FIG .5 (a) Microscopic examination showed spindle shaped cells arranged in short bundles and forming interlacing fascicles with nuclear palisading. Antony A and Antony B areas with verocay bodies (H and E; 10X). (b) Positivity for S-100 thus confirming the diagnosis $(10 \mathrm{X})$.

\section{Conclusion}

Schwanomas are usually asymptomatic, non - recurrent benign tumor that can go undetected for years . Clinical history and radiographic findings on MRI are required for diagnosis . Surgical excision is the best treatment modality

\section{References}

1. J. Galli, M. Imperiali, I. Cantore, L. Corina, L. M. Larocca, and G. Paludetti, "Atypica sinonasal schwanomas: a difficult diagnostic challenge,” Auris Nasus Larynx, vol. 36, no. 4,pp. 482-486, 2009

2. J. Hu, Y.-Y. Bao, K.-J. Cheng, S.-H. Zhou, L.-X. Ruan, and Z.- J. Zheng, "Computed tomography and pathological findings of five nasal neurilemmomas," Head and Neck Oncology, vol. 4, no.1, article 26, 2012

3. G. Broich, A. Pagliari, and F. Ottaviani, "Esthesioneuroblastoma: a general reviewof the cases published since the discovery of the tumour in 1924," Anticancer Research, vol. 17, no. 4A, pp. 2683-2706, 1997.

4. Gulia JS, Yadav SS, Basur SK, Hooda A. Schwannoma of the membranous nasal septum. Braz J Otorhinolaryngol 2013; 79: 789. [CrossRef]

5. Batsakis J. Tumours of the Head and Neck Clinical and Pathological Considerations.2nd ed. Baltimore, MD: Williams and Wilkins; 1979, 313-333.

6. Pauna HF, Carvalho GM, Guimaraes AC, Maunsell RC, Sakano E. Schwannoma of the nasal septum: evaluation of unilateral nasal mass. Braz J Otorhinolaryngol 2013; 79 403. [CrossRef]

7. Calceterra TC, Rich JR, Ward PW. Neurilemoma of the sphenoid sinus. ArchOtolaryngol 1974; 100: 383-85. [CrossRef]

8. Hegazy HM, Snydermann CH, Fan CY, Kassam AB. Neurilemmomas of the paranasa sinuses. Am J Otolaryngol. 2001;22:215-18.

9. Ross C, Wright E, Moseley J, et al. Massive schwannoma of the nose and paranasal sinuses. South Med. J. 1988:81:1588-1591

10. Younis RT, Gross CW, Lazar RH. Schwannomas of the paranasal sinuses: case report and clinicopathologic analysis. Arch. Otolaryngol. Head Neck Surg. 1991;117:677-680.

11. Rodriguez FJ, Folpe AL, Giannini C, Perry A. Pathology of peripheral nerve sheath [9] tumours: diagnostic overview and update on selected diagnostic problems. Acta Neuropathol. 2012;123:295-319.

12. Buttler RT, Patel RM, McHugh JB. Head and Neck Schwannomas: 20 year experience of single institution Excluding cutaneous and acoustic sites. Head Neck Pathol. 2016;10:286-81.

13. Kurtkaya-Yapcer Ö, Scheithauer B, Woodruff JM. The pathobiologic spectrum of [11] Schwannomas. Histol Histopathol. 2003;18:925-34. 